\title{
Electricity Markets in a Time of Change: A Call to Arms for Business Research
}

\author{
Martin Bichler · Hans Ulrich Buhl • Johannes Knörr · Felipe Maldonado • \\ Paul Schott · Stefan Waldherr • Martin Weibelzahl
}

Received: 1 December 2020 / Accepted: 25 November 2021 / Published online: 5 January 2022 (C) The Author(s) 2021

\begin{abstract}
Europe's clean energy transition is imperative to combat climate change and represents an economic opportunity to become independent of fossil fuels. As such, the energy transition has become one of the most important, but also one of the most challenging economic and societal projects today. Electricity systems of the past were characterized by price-inelastic demand and only a small number of large electricity generators. The transition towards intermittent renewable energy sources changes this very paradigm. Future electricity systems will consist of many thousands of electricity generators and consumers that actively participate in markets, offering flexibility to balance variable electricity supply in markets with a high spatial and temporal resolution. These structural changes have ample consequences for market operators, generators, industrial consumers as well as prosumers. While a large body of the literature is devoted to the energy transition in engineering and the natural sciences, it has received relatively little attention in the recent business research literature, even though many of the central challenges for a successful energy transition are at the core of business research. Therefore, we provide an up-to-date overview of key questions in electricity market design and discuss how changes in
\end{abstract}

Martin Bichler $(\bowtie) \cdot$ Johannes Knörr $\cdot$ Felipe Maldonado

Department of Informatics, Technical University of Munich, Boltzmannstr. 3, 85748 Garching,

Germany

E-Mail: bichler@in.tum.de

Hans Ulrich Buhl

FIM Research Center, Project Group Business \& Information Systems Engineering of the Fraunhofer FIT, Alter Postweg 101, 86159 Augsburg, Germany

Paul Schott · Martin Weibelzahl

FIM Research Center, University of Bayreuth, Project Group Business \& Information Systems

Engineering of the Fraunhofer FIT, Wittelsbacherring 10, 95444 Bayreuth, Germany

Stefan Waldherr

School of Business and Economics, Vrije Universiteit Amsterdam, De

Boelelaan 1105, 1081 HV Amsterdam, The Netherlands 
electricity markets lead to new research challenges in business research disciplines such as accounting, business \& information systems engineering, finance, marketing, operations management, operations research, and risk management.

Keywords Electricity market design - Energy transition - Renewable energy sources - Demand response

\section{Introduction}

Climate change and efforts to reduce greenhouse gas emissions represent a major challenge for our planet. The annual economic costs of climate change are estimated to amount to USD 2 trillion in 2050 if global temperature changes by $1{ }^{\circ} \mathrm{C}$ (Kemfert 2005). This temperature increase has already been surpassed today according to recent climate reports (IPCC 2018; World Meteorological Organization 2020). In particular, about $2.5 \%$ of the global GDP, or USD 2.4 trillion, of annual investments in energy systems are needed in order to limit global warming to a $1.5^{\circ} \mathrm{C}$ increase according to current estimations (IPCC 2018).

In line with the Paris Climate Agreement, many countries around the world are currently undergoing a far-reaching energy transition. A primary objective is to reduce greenhouse gas emissions by switching from fossil fuels to Renewable Energy Sources (RES) (Raftery et al. 2017). The energy transition provides opportunities to reduce the dependence on scarce fossil fuels and to build an economically and ecologically sustainable future (Glenk et al. 2021). Moreover, the energy transition is regarded as a key driver for the innovation, growth, and modernization of the economy (BMWi 2015). One aspect of the energy transition is a sharp increase of electricity demand due to an ongoing electrification and sector coupling (Keramidas et al. 2020). In this paper, we therefore address electricity markets as a central component of the energy transition. Thus, we are referring to the electricity sector when we mention the energy transition. In electricity markets, the necessary decarbonization efforts of the energy transition shift central paradigms and thereby shape economic and societal developments. A successful integration of an increasing share of RES, in particular of Variable Energy Resources (VER) such as wind and solar, requires changes in electricity market design to set adequate short- and long-term incentives for the various market participants and their assets.

Electricity markets have developed from monopolies to competitive wholesale markets, accompanied by changing governance and significant technological progress (Cramton 2017), and they continue to evolve in different ways. In light of the energy transition, ENTSO-E ${ }^{1}$ or IRENA ${ }^{2}$ expect several changes in the current (European) market design (ENTSO-E 2021; IRENA 2019b): (1) The shift towards smaller pricing zones or even nodal pricing to better reflect local scarcity and imbalances (spatial granularity), (2) the trend towards a higher temporal resolution and closer-to-real-time electricity trading (temporal granularity), and (3) an active

\footnotetext{
1 European Network of Transmission System Operators for Electricity.

2 International Renewable Energy Agency.
} 
and flexible demand side. These changes have ample consequences on all market participants, including market operators, electricity generators, industrial consumers, and retail customers, and most of the changes lead to managerial challenges.

In the past, topics in and around electricity markets have received some attention in business research (e.g., Stoft (2002)). Compared to engineering and natural sciences, however, there is only a small body of existing literature and no up-to-date overview of business research challenges in the context of the energy transition. To close this gap, this paper provides a brief summary of the status quo and the changes to be expected in electricity markets, and outlines new challenges for market participants as well as research opportunities that arise for the business research disciplines. While it is impossible to cover all research problems in this field, the paper should provide a convenient guide to the most pressing research problems in this domain for our field.

In collaboration with colleagues from outside the field (including, e.g., engineers, computer scientists, legal scholars, and economists), business research must play its role in successfully mastering the decarbonization of electricity systems and, thus, in actively shaping the energy transition. Overall, the paper is a call to arms for business research on what is arguably one of the most important economic and ecological topics of our time: the energy transition.

In Sect. 2, we will first provide an overview of electricity market design in Europe and in the US. These markets differ in key features, and there is plenty of literature comparing and contrasting respective market design aspects. This overview serves as a basis for understanding changes in electricity market designs that are about to come. In particular, there is an ongoing discussion if the large pricing zones (e.g., as in European markets) are suitable to integrate increasing levels of VER. We also discuss the time granularity in electricity markets and the impact of an active demand side.

With this understanding, we illustrate the main research challenges for business research disciplines with regard to the relevant stakeholders in electricity systems, i.e., market operators (cf. Sect. 3), generators (cf. Sect. 4), industrial consumers (cf. Sect. 5), and prosumers (cf. Sect. 6). We outline possible contributions of several business research disciplines such as accounting, business \& information systems engineering, finance, marketing, operations management, operations research, and risk management. Finally, we conclude with a summary in Sect. 7.

\section{Electricity Market Design}

The fundamental objectives of electricity market designs are the efficient and reliable supply of electricity (Cramton 2017). This translates into both a short-run welfaremaximizing dispatch and adequate price signals for efficient long-run investments in electricity system assets (Bublitz et al. 2019; Stoft 2002; Hogan et al. 2005). Other market design objectives include simplicity, transparency, and fairness (Cramton 2017).

In the 1990s, both European countries and the US liberalized their energy systems and developed different electricity market designs. There is a vast literature 
associated with those markets, both in form of research papers and public reports, highlighting similarities and differences between central design features in these electricity markets. While many of the described features can also be observed in other markets, the study of European and US markets helps to understand changes due to the energy transition and their impact on various stakeholders.

\subsection{Market structure}

Short-term electricity procurement is nowadays largely carried out via power exchanges, i.e., on spot markets. These power exchanges determine central price signals for over-the-counter trades and futures markets (Shah and Chatterjee 2020). For example, in Europe, day-ahead markets are seen as a reference for forward markets. Due to, e.g., changing weather forecasts, generation and demand are subsequently adjusted on intraday markets. Finally, Transmission System Operators (TSOs) procure the necessary electricity to ensure system stability in balancing markets. Figure 1 illustrates the basic structure and time sequence of European (top) and US (bottom) electricity markets. ${ }^{3}$

European and US electricity markets differ in their bidding formats and market clearing rules across the different markets. Liberalized US markets are centered around an Independent System Operator (ISO), which assumes the role of both market and system operator and, thus, centrally optimizes the scheduling (allocation

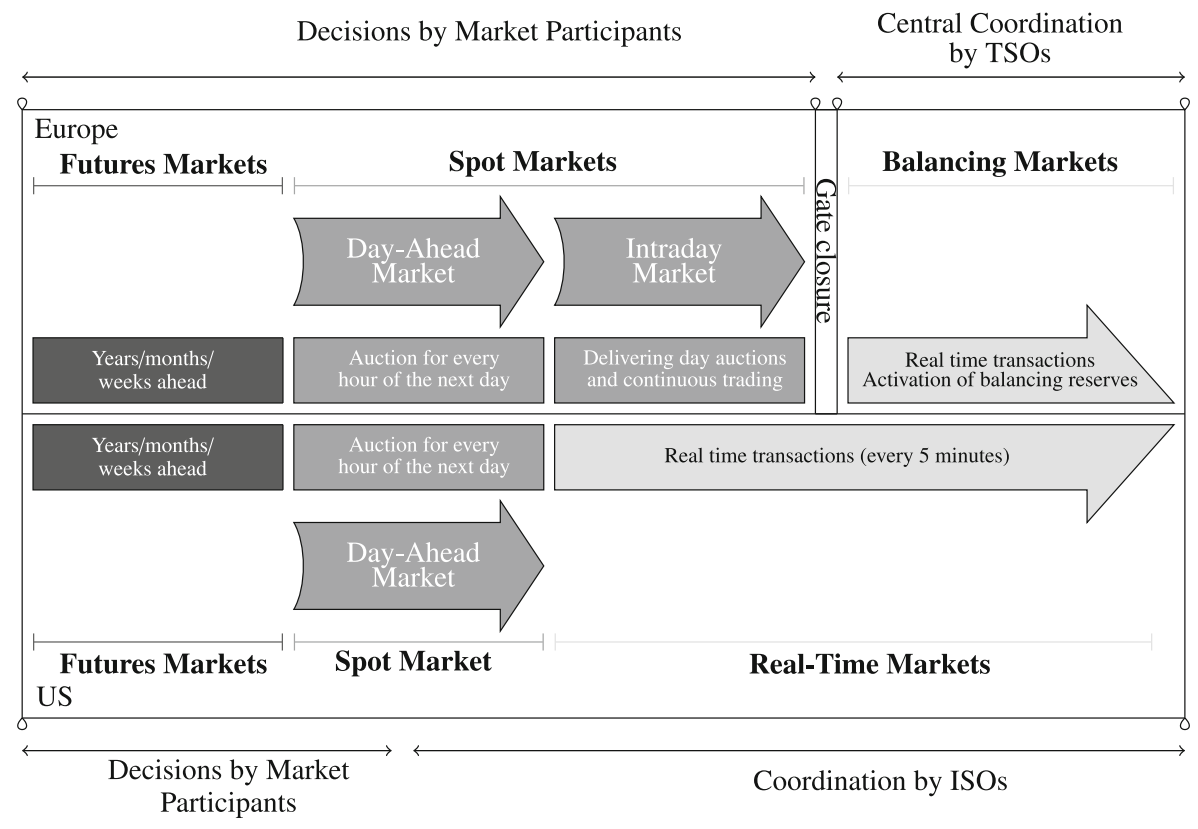

Fig. 1 Overview of European and US electricity markets

\footnotetext{
3 The figure is loosely based on https://www.amprion.net/Market/Market-Report/Overview-ElectricityMarkets-in-Europe/.
} 
plan) and the dispatch (real-time control of resources) (Cramton 2017). Examples for such ISOs include CAISO in California, MISO in the Midwest, or PJM in Pennsylvania, New Jersey, and Maryland. After the electricity crisis of California in 2000, many electricity markets in the US have undergone reforms, which have been widely reported and studied (Borenstein and Bushnell 2015; Kwoka 2008; Hogan 2002). Especially the gains in efficiency have been prominently highlighted (Borenstein and Bushnell 2015; Cramton 2017). Many other countries have since adopted a pool model similar to the ones in the US. For instance, several South American countries (Palma Behnke and Alarcón Arias 2009), but also Canada and Australia ${ }^{4}$ follow a similar model 5 .

In Europe, the historic development from strongly regulated to liberalized markets was similar in different countries, as it was strongly driven by common European legislation. Electricity markets in Europe build on the concept of exchange-based zonal markets (Cramton 2017), where system operation is decoupled from market operation. Unlike in the US, market operation is carried out by separate Nominated Electricity Market Operators (NEMOs). The NEMOs collect all bids and match supply and demand. Meanwhile, TSOs administer the electricity grid and are responsible for system security, i.e., the balance of supply and demand at every location of the grid and for every point in time. It is worth noting that European electricity markets are coupled, meaning that a coordinated market clearing is performed across different countries for the central day-ahead market by means of the Pan-European market coupling algorithm EUPHEMIA ${ }^{6}$ (Adamec et al. 2009; Meeus et al. 2009a). The market coupling in Europe leads to significant computational complexity, which is going to increase as we see more active participants and as Eastern European markets join the common platform (NEMO Committee 2019). This is different to the US, where ISOs have a well-defined, limited geographical scope and are either completely decoupled from other markets (e.g., ERCOT) or only loosely interconnected (e.g., PJM and New York ISO) (Herrero et al. 2020).

Another important difference to US ISO markets is the bid language provided by European NEMOs. The main elements of the European bid language are simple hourly orders (allowing to express price and quantity) and block orders. Regular block orders are buy or sell orders for a period of consecutive hours that can only be accepted in total or not at all. Various versions of these basic formats are available in different NEMOs (Herrero et al. 2020). It has been criticized that the bid language does not adequately address the need of market participants (Herrero et al. 2020). Market participants often need to submit an unreasonable amount of (block) bids to appropriately express their preferences, increasing computational complexity. As a consequence, there is a discussion about the introduction of multi-part bids for

\footnotetext{
${ }^{4}$ Further information can be found under https://www.energy.gov.au/government-priorities/energymarkets/national-electricity-market-nem.

5 Much less literature is available about the Chinese market. However, after a large reform in 2015, the electricity market in China moved from a state-owned monopoly to a market-oriented system, where both public and private companies participate. The market is based on bilateral contracts and double-sided auctions (Lei et al. 2018).

6 Pan-European Hybrid Electricity Market Integration Algorithm.
} 
different types of participants, consisting of start-up costs, no-load costs, and variable costs similar to US ISO markets (Herrero et al. 2020; Richstein et al. 2020).

Moreover, while simple bids in EU NEMOs are fully accepted if the strictly uniform price is above the generation offer, this is typically not possible with block bids (Bichler and Waldherr 2017). As a result, there are welfare losses (Meeus et al. 2009b) and paradoxically rejected bids - block bids that are in-the-money, but still rejected. For instance, if the offer price of a sell block bid is lower than the average uniform price during the block period, it would be overall profitable to accept the block bid. Under European market clearing rules, however, the block bid could be fully rejected. Such rejected bids are considered "the most relevant concern nowadays in European markets" (Herrero et al. 2020). The joint response of the Agency for the Cooperation of Energy Regulators and the Council of European Energy Regulators to the European commission's Consultation on a new electricity market design states: "We would particularly like to see clearer rules and greater transparency around the market coupling algorithm (EUPHEMIA)" (Agency for the Cooperation of Energy Regulators 2015).

European and US ISO electricity markets illustrate how liberalized electricity markets can differ in their specific designs. However, both markets need to incorporate increasing VER capacities. Three major developments are likely to accompany this energy transition: (1) the spatial granularity of prices, (2) the temporal granularity of market processes, and (3) an active demand side (IRENA 2019b).

\subsection{Spatial granularity of prices}

Since 2010, all US ISOs compute separate prices for each node in the electricity grid and each time period (Bohn et al. 1984; Chao and Peck 1996; Hogan 2002; Herrero et al. 2020), commonly named Locational Marginal Prices (LMPs). ISOs employ mixed-integer programming to solve the unit commitment problem (scheduling) and to compute the efficient dispatch of generators as well as LMPs. At any given point in the network, LMPs measure the marginal cost of delivering an additional unit of electricity to that corresponding location. Thereby, LMPs reflect the local availability as well as demand for electricity. LMPs also explicitly account for relevant grid constraints as well as for costs of grid losses. The solution to the clearing problem determines a dispatch that does not require costly ex-post corrective measures, i.e., congestion management or redispatch. Moreover, LMPs send adequate long-run investment signals for generation and grid capacity (IRENA 2019a; Antonopoulos et al. 2020). This is especially relevant for the current transformation of electricity systems, in particular the spatial allocation of increasingly decentralized VER (Schmidt and Zinke 2020). In the US, price differences between nodes in the electricity system are typically small and only arise if the transmission network is congested (Cramton 2017). However, pricing in US ISO markets is still changing in an attempt to reduce the weight of uplift and to internalize all operational costs into market prices (Herrero et al. 2020).

In European electricity markets, various network nodes are aggregated into larger bidding or pricing zones, resulting in uniform (identical) prices within a zone. The design is similar to early US wholesale markets (Wolak 2021). Market partici- 
pants can trade unlimited electricity within a zone, regardless of underlying grid constraints. Since capacity constraints of intra-zonal transmission lines are largely ignored when trading electricity, frequent and expensive corrective measures by the TSOs are needed in order to mitigate congestion and to maintain operational security. Such measures lead to high costs: In Germany, the TSOs reported redispatch and countertrading costs that went from EUR 41.63 millions in 2011 to over EUR 1 billion in 2019 (Bundesnetzagentur and Bundeskartellamt 2021). In the first half of 2021, the TSOs in Germany have already reported costs of about EUR 650 million. ${ }^{7}$ This contributes to welfare losses in the European zonal system (Grimm et al. 2020; Weibelzahl 2017).

The following two-nodes example aims at illustrating the differences between LMPs and uniform prices.

Example 2.1 In Fig. 2, we consider a simple two-nodes example for a single hour. There exists one generator at each node, $G 1$ and $G 2$, with marginal costs (MC) of 10EUR/MWh and 20EUR/MWh, respectively. Both generators have a maximum capacity of $1000 \mathrm{MW}$. The transmission line that connects both nodes does not suffer from losses but it has a maximum capacity of 500MW. Demand at nodes 1 and 2 is $100 \mathrm{MWh}$ and $600 \mathrm{MWh}$, respectively. According to these parameters, the efficient solution will be for $G 1$ to produce $600 \mathrm{MWh}$, supplying $100 \mathrm{MWh}$ for node 1 and $500 \mathrm{MWh}$ for node 2 . The remaining $100 \mathrm{MWh}$ for node 2 will be provided by $G 2$. The respective LMP will be 10EUR/MWh for node 1 and 20EUR/MWh for node 2 (marginal cost of producing an additional unit). In contrast, uniform pricing would ignore the transmission-capacity limit and set a uniform price of 10EUR/MWh (as $G 1$ would satisfy the entire demand). R). However, considering the transmission capacities, there is no feasible dispatch at this price that satisfies demand. As a result, a redispatch by the TSO is required to arrive at a balanced electricity grid. The costs for this redispatch are added as network tariffs to the wholesale price and have been increasing for years.

In electricity markets with zonal pricing as in Europe, the increase in shortterm intermittent and decentralized electricity generation of VER leads to various challenges due to the insufficient consideration of increasingly binding transmission constraints (due to decentralized VER) and technical generation constraints (given shorter operating cycles) (Wolak 2021). LMPs (to account for transmis-

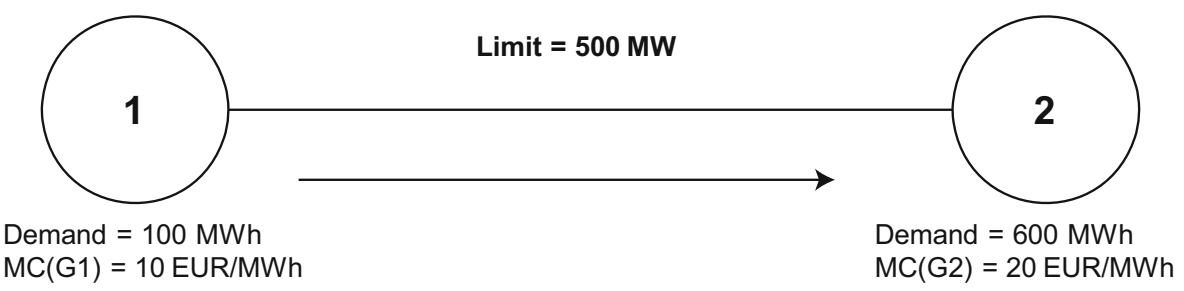

Fig. 2 Simplified example of LMPs and uniform prices

\footnotetext{
7 More data are accessible under https://transparency.entsoe.eu/dashboard/show.
} 
sion constraints) and advanced bid languages (to better express technical constraints) are widely regarded as important aspects for a future-proof electricity market (Antonopoulos et al. 2020). Many experts argue that a shift from zonal prices to nodal pricing, i.e., LMPs, is inevitable in Europe to efficiently deal with grid congestion, and to incentivize efficient investments in grid, generation, or flexible demand assets (Ashour Novirdoust et al. 2021). However, the move to LMPs has significant consequences, not only for the design of spot markets itself, but also for electricity generators or industrial and retail consumers, as we will see.

\subsection{Temporal granularity of market processes}

Similar to the spatial granularity of prices, there is evidence that a higher temporal resolution of market clearing is important in the presence of large amounts of VER. A more frequent trading and scheduling allows to react to (unexpected) short-term deviations in both the supply and the demand for electricity, which affects the balance between electricity consumption and generation. Moreover, moving the gateclosure closer to the physical delivery allows for near real-time corrections of the schedule and reduces the need for redispatch. There are arguments that this leads to higher incentives for flexible assets and active demand response (IRENA 2019b). However, an implementation of higher temporal granularity of market processes needs to respect the possibilities and needs of market participants. For example, smaller participants might not be able to maintain a 24-hour trading desk.

Regarding the temporal resolution of prices, continuous intraday markets on EPEX Spot currently offer the possibility of 60 minutes, 30 minutes, and 15 minutes products. Moreover, the gate-closure time was shortened in many European countries to allow for more short-term electricity trading. For instance, EPEX Spot allows for continuous intraday trading until 30 minutes before the actual physical delivery. If the trade takes place within a control zone of a TSO, the gate-closure time is even only 5 minutes (Fridgen et al. 2020). Similar dispatch intervals (15 and 5 minutes or even down to 1 minute) occur in US ISO real-time markets (California ISO 2019a). Furthermore, in day-ahead markets, 15-minute contracts are currently in the works both in the coupled European market (NEMO Committee 2021) as well as in US ISOs (California ISO 2019b), in order to complement and replace conventional hourly products.

\subsection{Active demand-side bidding and flexibility}

The academic literature on electricity market pricing almost exclusively relies on the assumption of price-inelastic demand (Liberopoulos and Andrianesis 2016). This assumption stems from a time where a few large and dispatchable electricity generators had to satisfy the given demand of consumers over time. The characteristic intermittency and uncertainty of many VER require an integration of various flexibility options in order to guarantee the required balance between electricity generation and consumption at all times (Reihani et al. 2016). This leads to a growing need for additional and new flexibility to counteract the increasing generation intermit- 
tency (Papaefthymiou et al. 2018), including flexibility options on the demand and supply side, storage, as well as grid flexibility (Lund et al. 2015).

Demand-side flexibility is generally a cheaper flexibility option compared to storage technologies (EU 2016), fostering the large-scale integration of VER (Alemany et al. 2018). However, the potential of demand-side flexibility is still largely untapped. For example, industrial processes for the production of pulp and paper could provide flexibility with a duration of up to three hours without any prior notice period (EU 2016). Beyond industrial companies, there is a large potential for demand-side flexibility also in the retail market, including smart charging of electric vehicles (and the electrification of sectors other than transportation) or smart appliances in residential and commercial buildings (IRENA 2019a; Paukstadt and Becker 2021). If organized into virtual power plants (VPPs), such new players can also actively bid into the market.

Currently, there is only a small amount of demand that actively bids into markets, but this is expected to change (Hytowitz et al. 2020). For instance, the recent order 2222 by the US Federal Energy Regulatory Commission (FERC) from October 2020 demands US ISOs to allow for an active demand side and distributed energy resources to bid in wholesale markets. A finer spatial and temporal resolution of electricity markets can also increase flexibility incentives for the system (IRENA 2019b).

In summary, the intermittent nature of VER has ample effects on electricity market design. We can expect to see a higher temporal and spatial granularity of prices and a more active participation of the demand side. However, the changes about to come do not only affect the electricity market in the narrower sense, but they impact all market participants including generators, industrial, and retail consumers. Therefore, the next sections discuss changes for market operators, electricity generators, industrial consumers, and prosumers. We outline various challenges for each of these players and emphasize contributions that the business research community can make.

\section{Market Operators}

The discussion of challenges of market operators in this section will focus on two major aspects. On the one hand, the growing number of market participants, e.g., due to an active demand side and a more decentralized supply side, together with (new and existing) non-convexities of the underlying central welfare-maximization problem, lead to various computational challenges. This raises the question of how the efficient dispatch in an electricity network can be computed efficiently. On the other hand, current pricing rules are under scrutiny. Welfare-maximizing markets often require high side-payments, constituting a clear sign of inefficient pricing. Therefore, the second challenge refers to the question of how market operators can compute prices in modern electricity markets and which properties (e.g., competitive equilibrium, individual rationality, or budget balance) we can hope to achieve. 


\subsection{How can the optimal dispatch in an electricity market be computed efficiently?}

Let us first introduce the generic welfare maximization problem that a market operator has to solve in central dispatch markets with a high spatial price granularity and an active demand side. The problem is split into an initial unit commitment problem, determining which resources are committed for the time period under consideration, and a subsequent economic dispatch problem, which determines the operating level of every committed resource. As these problems account for grid constraints, the respective literature in operations research also refers to optimal power flow (OPF) problems that market operators need to solve. We briefly outline the main objective and constraints of OPF models in an informal manner:

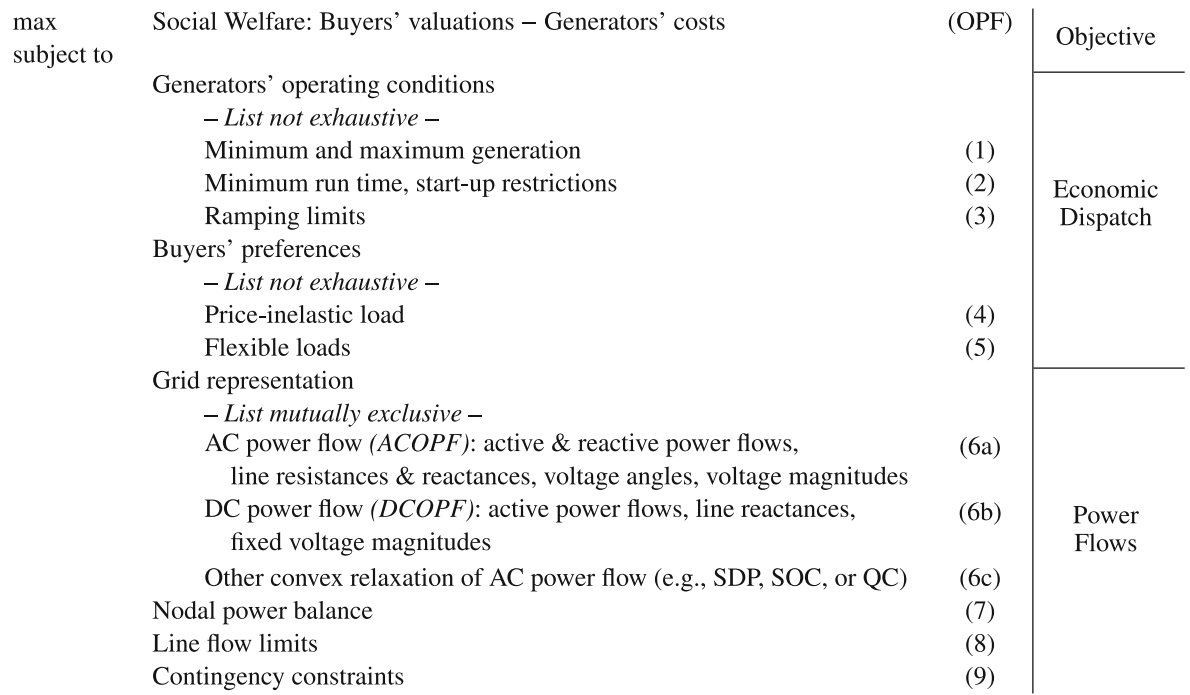

The OPF is based on the submitted bids (according to the provided bid language) and takes into account the generators' costs and operating conditions (1-3), typically including minimum and maximum electricity generation, ramping restrictions, or minimum runtimes after a start-up for each generator. It also considers buyers' valuations and constraints expressing buyers' preferences as well as flexibilities (4-5). Physical constraints of the electricity grid are given in (6a-6c), as discussed below. Moreover, at each node, the net total of demand, generation, and power flows needs to be strictly balanced (7) and the flow limits of transmission lines must not be violated (8). The OPF problem can also include additional contingency constraints to consider unexpected events and outages, often referred to as security-constrained OPF (Cain et al. 2012).

A major challenge with respect to the computation of the efficient dispatch is the network representation $(6 \mathrm{a}-6 \mathrm{c})$. Generally speaking, the so-called AC optimal power flow (ACOPF) model correctly incorporates the underlying physics that govern power flows (Cain et al. 2012). It includes a set of non-convex non-linear 
constraints, describing the power flow on each transmission line (Carpentier 1985). Considering various integer variables required in the OPF, the ACOPF thus turns out to be a non-linear mixed-integer optimization problem (Zohrizadeh et al. 2020). In spite of advances in global optimization, the ACOPF can be regarded intractable for practical problem sizes. To put this into perspective, the operating region of the California ISO covers 26,000 circuit miles, roughly 1000 power plants, a population of 30 million, and about 9700 pricing nodes (California ISO 2018). Solving ACOPF problems of that size is out of reach for state-of-the-art techniques in global optimization.

Currently, there is significant research into convex relaxations and approximations of the ACOPF (Zohrizadeh et al. 2020). The linear approximation of the AC power flow equations is referred to as the direct current optimal power flow (DCOPF) model. It is used among ISOs in the US to compute the efficient dispatch and prices in their network (Eldridge et al. 2017). However, it comes with certain limitations, e.g., it neither models all line resistances nor reactive power flows.

Therefore, the DCOPF implementations in use today often result in solutions that must be iteratively checked for physical feasibility (in the ACOPF) before implementation (O'Neill et al. 2011). The development of solution methods providing physically feasible and tight solutions within the - increasingly narrowing - time limits required for practical application remains an open problem, and one that provides plenty of opportunities for the operations research community (Qiu et al. 2009; Frank et al. 2012; Castillo and O'Neill 2013; Molzahn et al. 2019; Low 2014a,b). Promising convex relaxations include the Semi-Definite Programming (SDP) relaxation (Bai et al. 2008; Coffrin et al. 2016), the Second-Order Cone (SOC) (Jabr 2006), the Convex-DistFlow (CDF) (Farivar et al. 2011), the Quadratic Convex (QC) relaxation (Hijazi et al. 2017), and Moment-Based (Molzahn and Hiskens 2014) approaches. Distributed and parallelizable OPF algorithms provide another way forward to incorporate large numbers of distributed VER (Sun et al. 2013). The ARPA-e grid optimization competition ${ }^{8}$ in 2020/21, awarded with USD 2.3 million, emphasizes the relevance of this research. In summary, solving optimal power flow problems in markets with locational price signals poses a fundamental research challenge for operations research.

\subsection{How can prices be computed in modern electricity markets and which properties can we hope to achieve?}

Regardless of the choice of the power flow model, the inherent non-convexities of the OPF due to integer variables required to model, e.g., fixed costs or minimum loads, lead to challenges in the pricing. Ideally, market operators could compute Walrasian prices on electricity spot markets. Walrasian prices describe linear (single price for each good or hour of the day) and anonymous (identical prices for every bidder) competitive equilibrium prices (Arrow and Debreu 1954). At such prices, every participant maximizes payoff and the budget is balanced. In other words, the market does not require any subsidy and the outcome is stable. Several papers dis-

\footnotetext{
${ }^{8}$ More information is available under https://gocompetition.energy.gov/.
} 
cusses conditions for when a Walrasian equilibrium exists (Kim 1986; Bikhchandani and Mamer 1997; Baldwin and Klemperer 2019; Leme 2017; Bichler et al. 2020). Unfortunately, these assumptions are not satisfied in non-convex electricity markets.

As a consequence, several pricing rules have been developed to mimic such equilibrium prices (Liberopoulos and Andrianesis 2016). For instance, many practical implementations of LMP rules in US ISOs are based on Integer Programming (IP) pricing, where prices on a node in the transmission network are set to the dual of the nodal power balance constraints (Constraint 7 of the OPF model) of the linear program resulting from fixing the integer variables of the DCOPF to their optimal values. IP prices are linear and anonymous, yet do not constitute a competitive equilibrium. Prices are often not even individually rational, meaning some market participants incur losses when payments are limited to market price settlements (O'Neill et al. 2005).

In order to avoid losses, ISOs introduce personalized side-payments to either incentivize all market participants (lost opportunity cost payments) or only to ensure individual rationality (make-whole payments) (Schiro et al. 2016). The latter form of payment is mostly used by ISOs, since stability can be achieved differently in the highly regulated environment of electricity markets. Actually, most ISOs stipulate penalties for deviating from the optimal dispatch (Hytowitz et al. 2020). Under either form of compensation, the payments to market participants are now personalized and non-linear, despite the linear and anonymous market prices.

However, even the make-whole payments have recently come under scrutiny (Hytowitz et al. 2020). The US FERC as the relevant supervisory authority found current practices to be unjust and not accurately reflecting the cost of serving load (O'Neill et al. 2019). As the make-whole payments are not reflected in the public price signal, investment signals and references for hedging markets are distorted. Therefore, the FERC has released several orders saying that "the use of side-payments can undermine the market's ability to send actionable price signals" (Federal Energy Regulatory Commission 2020).

The question of electricity pricing becomes even more pressing if an active demand side is considered. Unfortunately, such price-sensitive bids for flexible demand often lead to additional integer variables and computational hardness. Besides, many pricing rules in the literature cannot easily be extended to markets with price-sensitive demand. For instance, the Semi-Lagrangian pricing rule (Araoz and Jörnsten 2011) fundamentally rests on the notion of price-inelastic demand.

Initial proposals try to address these problems via price differentiation on the demand-side (O’Neill et al. 2019) or via bid-ask spreads (Toczyłowski and Zoltowska 2009). However, the literature barely scratches the surface of what turns out to be a fundamental problem, that of general equilibrium in markets with indivisible goods and non-convex preferences.

\section{Electricity Generators}

The transition to higher VER capacities with an increasing number of generation units have ample effects on the generation structure and market design needs. 
VER typically exhibit near-zero marginal costs, thereby pushing conventional power plants backwards in the merit order. This is commonly referred to as the merit order effect (Sensfuß et al. 2008; Gelabert et al. 2011; Woo et al. 2011; Clò et al. 2015). Together with the changing spatial and temporal granularity of market prices, the merit order effect impacts the revenue opportunities of generators.

This section outlines new challenges for generator business models and how market design can help to address such aspects. Here, a number of open questions remains regarding the specific design and the impact of instruments to ensure appropriate market-based remuneration. Moreover, individual or collective over-thecounter arrangements to trade electricity receive increasing attention. We discuss how business research can contribute to enhancing and fostering such novel business models.

\subsection{How can generator business models with market-based remuneration persist with increasing VER capacities?}

As discussed in Sect. 2, the increasing penetration of intermittent and decentralized electricity generation stimulates a shift towards spatially and temporally fine-grained prices. Market design aims to achieve both a short-run efficient market clearing as well as appropriate remuneration mechanisms to promote long-run efficiency and stability. Business research disciplines can provide fruitful insights that contribute to the development of sustainable business models under these circumstances.

Generator business models are - generally speaking - based on creating revenues from (wholesale) electricity markets by selling electricity at the respective market price. As market prices exhibit an increasing spatial and temporal resolution, wholesale revenues and (locational) investment incentives are affected, as noted by several studies on nodal pricing (Ashour Novirdoust et al. 2021; Schmidt and Zinke 2020; Dijk and Willems 2011). There is evidence that smaller price zones promote efficient and location-specific long-run investments (Grimm et al. 2016; Munoz et al. 2018). However, there is also a need for robust prices to contribute to stable business models with reliable market remuneration and proper investment signals (Antonopoulos et al. 2020). Therefore, appropriate hedging instruments and risk management tools need to complement generator business models when market remunerations experience a higher variability. The finance community can contribute to designing respective products. For example, financial transmission rights (FTRs), originally introduced by Hogan (1992), are established tools in US ISO markets to hedge point-to-point price risks. In essence, FTRs pay the holder the difference between a pre-defined pair of day-ahead locational prices.

The payoffs for FTRs are typically funded from so-called congestion revenues. Congestion revenues originate if a supplier and a consumer of electricity are located at nodes with a price difference due to congestion. Both the seller's and the buyer's orders are settled at the respective locational price, and the market operator collects the price difference. Referring back to Example 2.1, the market operator would receive $(100 \times 10+600 \times 20) \mathrm{EUR}=13,000 \mathrm{EUR}$ from the consumers and pay $(600$ $\times 10)$ EUR to $G 1$ and $(100 \times 20)$ EUR to $G 2$. The remaining 5000EUR constitute the congestion revenue. However, it has been noted that congestion revenues might not 
be able to cover the payoffs of FTRs (Hogan 2013), which remains an open problem. There have been first attempts to incorporate this shortfall of congestion revenues into the pricing rule (Garcia et al. 2020). The missing money problem is also related to allocation mechanisms for FTRs. An equitable and effective allocation of FTRs is desired, and auctions are a preferred medium to achieve this. While mathematical models for FTR auctions have been long proposed (Alomoush and Shahidehpour 2000), inherent flaws in the auction clearing algorithm have been discovered that cause systematic discrepancies between the FTR clearing price and the FTR payoff (Deng et al. 2010). This calls for contributions by market design and operations research to design appropriate auctions and secondary markets. Generator business models can evolve and adapt to new circumstances only with functioning hedging instruments and markets. The level of detail of PJM's review on FTRs highlights the relevance and complexity of this topic (London Economic International LLC 2020).

Generator business models are also affected by an increasingly active demand side that allows to balance the intermittency of renewable electricity supply. Flexible demand tends to become a dispatchable resource and can be coupled with variable generation (Sioshansi 2021). Many conventional generators might, thus, be driven out of the merit order frequently, and the lack of constant market remuneration challenges current business models. However, scarcity periods (i.e., the infamous dark doldrums) may still require conventional back-up generators or real-time reserve capacity to ensure a reliable supply of electricity. Therefore, generator business models can - and to some extent must - shift from the role of baseload suppliers with continuous revenues to the role of stand-by facilities to provide electricity in times of scarcity.

In the described scarcity periods, the key parameters for functioning business models based on market remuneration are the scarcity prices. (Cramton 2017). Scarcity pricing describes situations when electricity prices rise above the marginal cost of electricity in situations of system stress and a lack of generation capacity. Scarcity prices are deemed essential to attract investments in times of increasing VER capacity (Papavasiliou 2020). While implemented in some US ISOs, scarcity pricing has been hardly studied in the European context, despite being mentioned favorably in the Clean Energy Package (Papavasiliou 2020). Business research disciplines could contribute to developing appropriate scarcity pricing concepts that enable business models where generators run profitably despite an expected low number of operating hours per year (Papavasiliou 2020; Hogan 2013). Generator business models need to be in harmony with design choices on scarcity pricing, e.g., under which circumstances scarcity pricing is activated and how scarcity prices are determined (e.g., by an operating reserve demand curve). Overall, a collaboration between business research disciplines such as finance, market design, or operations could prove fruitful to design sustainable scarcity pricing schemes along with generator business models.

In addition, conventional generation producers might complement their business models with additional VER assets in order to reduce the $\mathrm{CO}_{2}$ emissions of their power plant fleet. New standards for reporting and voluntary disclosure could increase the visibility of emission reductions in their financial/business reports and 
thereby attract new investors or customers, which raises an interesting research direction for the accounting discipline.

\subsection{How can over-the-counter arrangements contribute to sustainable generator business models?}

Aside from market-based remuneration, generator business models can also rely on over-the-counter agreements to allow for calculable electricity prices, to enable appropriate hedging, or to increase generators' willingness to invest under uncertain revenues (IRENA 2017). For instance, so-called Power Purchase Agreements (PPAs) are bilateral and often long-term contracts between electricity suppliers and consumers. The contractual agreements can be customized, e.g., with respect to the nature of the contract (physical or financial) or the terms of payment and delivery. PPAs are an increasingly attractive instrument for VER to recover investment costs (Ghiassi-Farrokhfal et al. 2021).

PPAs promise interesting research questions for the business research community. The domain of PPAs is described as "still finding its feet" (Schilling 2019) due to a lack of standardization and widely diverging contract terms. Developing robust standards and comprehensive frameworks for PPAs, especially in light of an increasingly active demand side and spatially and temporally fine-grained prices, can facilitate their applications and help identify viable business models (Bruck et al. 2018; Mendicino et al. 2019).

Standardized PPA frameworks can also mitigate flawed incentives that are currently experienced with poorly designed PPAs. For example, PPAs have been found to incentivize uneconomic firms to remain in the market and economic firms to restrict their output (Chaiken et al. 2021). There is also evidence that sellers misreport their availability of electricity to increase profits (Wu and Babich 2012). Appropriate risk allocation mechanisms (Wu and Babich 2012) or decision support systems to configure PPAs (Ghiassi-Farrokhfal et al. 2021) can set correct incentives and create win-win situations for all contract parties, and deserve greater attention with changing market circumstances.

Moreover, the valuation of PPAs constitutes a challenge on its own. Depending on the contract terms, the value of a PPA depends on several factors, such as the expected electricity generation or the development of electricity prices (Schilling 2019). Especially for long-term contracts, expected electricity prices are hardly robust, and additional hedging strategies for price risks might be reasonable. Additional basis risks occur if the contract parties are located in different price zones. Due to their nature as over-the-counter agreements, PPAs are also subject to counterparty risks (Schilling 2019). Appropriate risk management tools and accounting methods for PPAs would be a considerable contribution to foster the usage of PPAs where it is appropriate.

PPAs are not the only conceivable over-the-counter arrangements that can complement generator business models. In the US, where the use of PPAs is already established, alternative finance structures for renewable energy projects are explored as well (Raikar and Adamson 2020). In the German market, so-called Bürgerenergiegesellschaften provide legal foundations for an active financial participation of 
citizens in generation facilities and in the energy transition (trend:research $\mathrm{GmbH}$ 2013). Similarly, the EU Clean Energy Package recognizes so-called Energy Communities as means to involve citizens in the energy transition (Caramizaru and Uihlein 2020). Such arrangements have not yet fully matured. Therefore, as for PPAs, questions with regard to the standardization or valuation of such agreements arise and could be addressed by business research disciplines.

\section{Industrial Consumers}

In many countries around the world, the industrial sector accounts for a large share of electricity consumption. By actively managing their demand, industrial consumers can contribute to an integration of VER by closing the emerging flexibility gap (Papaefthymiou et al. 2018). At the same time, industrial consumers can decrease their electricity cost (e.g., by exploiting time-varying prices) or reduce their $\mathrm{CO}_{2}$ footprint (e.g., by aligning the operations of own combined heat and power plants with the current $\mathrm{CO}_{2}$ intensity of the wholesale electricity mix) with a flexibilization of their electricity demand (Haupt et al. 2020; Wichmann et al. 2019b).

In general, demand-side management can be classified into two approaches: energy efficiency and demand response (Palensky and Dietrich 2011). While energy efficiency refers to the amount of output that can be produced with a given input of energy, demand response relates to deliberate changes in electric usage from the originally planned consumption patterns in response to, e.g., changes in the electricity price over time. In the following, we will focus on demand response.

In particular, we address two challenges related to demand response of industrial consumers. First, new system uncertainties resulting from the energy transition and market design changes towards a higher spatial and temporal granularity affect incentives for corresponding flexibility investments. Second, acting as an active participant in markets with fine-granular prices impacts production scheduling and operations planning, also leading to new research directions.

\subsection{How can uncertainties with respect to flexibility investments be addressed?}

On a strategic level, industrial consumers need to make long-term decisions as to whether and how to invest in demand flexibility, e.g., with the aim to reduce costs or $\mathrm{CO}_{2}$ emissions. In particular, industrial consumers need to invest in additional production capacities or the underlying production infrastructure in order to increase their flexibility potential (Schoepf et al. 2018; Wichmann et al. 2019a). Moreover, industrial consumers need to invest in an information and communication infrastructure to be able to automatically exploit their flexibility (Schott et al. 2019). When making their optimal flexibility investments, companies have to take into account that a flexible production may be associated with additional operating costs (Schott et al. 2019). For example, production machines often need to leave their optimal point of operation when exploiting demand flexibility. In this respect, there is limited experience about the effects of a flexible operation on maintenance and on a possibly shortened lifetime of machines. For instance, in thermal processes, greater and more 
frequent temperature deviations resulting from flexibility can lead to higher levels of wear. One possible direction to close this existing knowledge gap is to make use of so-called digital twins that can be developed and applied to represent production processes (Kender et al. 2021). An exemplary research question could be to what extent and how digital twins can also serve to determine costs resulting from the use of flexibility. For example, increased wear due to a more frequent startup and shutdown of (flexibly operated) processes can be analyzed.

In addition to unknown additional operating costs, new revenue opportunities or electricity cost saving opportunities of a flexibility supply must be taken into account for flexibility investments. In many cases, electricity cost savings (or revenues) of industrial consumers on different flexibility markets are too uncertain and too far in the future, which may hinder industrial consumers from investing in a flexible production. Here, the finance discipline could design products and services that allow energy-intensive consumers to effectively hedge against economic risks and thus create a plannable environment for investments in energy flexibility, e.g., in additional production capacities. In the literature, initial work already exists that deals with flexibility insurances for industrial companies (Jäckle et al. 2019). In particular, an insurer guarantees companies a minimum revenue associated with their flexibility marketing, while the companies pay the insurer an insurance premium. Even though the authors provide evidence that flexibility insurances can be a meaningful instrument for industrial companies to effectively mitigate economic risks, numerous unanswered research questions arise as to what constitutes the key drivers of these economic risk, how risk transfer instruments can be designed to best mitigate economic risks, and how issuers of flexibility insurances can manage inherent portfolio risks and diversify their portfolio.

\subsection{How do variable energy prices and demand response impact production scheduling and operations planning?}

Acting as an active and flexible consumer in electricity markets requires the ability of integrating the fluctuating electricity supply and volatile prices as well as the flexibility options into the scheduling procedures employed in production planning. While demand response models have not yet found widespread implementation, research in operations management and scheduling has long been active in investigating production processes that incorporate demand response. Cui and Zhou (2018) give an overview of a large variety of methods and techniques where production scheduling problems are extended by integrating energy prices and possibilities for flexible production. These extensions, however, increase the dimension of the mathematical models used to solve the scheduling problems and thereby also the computational demand for finding solutions. For example, the sequencing problem of production processes now needs to incorporate more decision variables as to how to split or shift processes. As a result, it often becomes impossible to find exact solutions for these large models.

Most current approaches to generate schedules for demand response problems rely on generic mixed-integer linear programming (MILP) formulations and metaheuristics. Historically, scheduling algorithms led to the best results when specific 
structures of (near-)optimal solutions could be identified. For example, in the domains of staff rostering (Aickelin and Dowsland 2000) and routing (Arunapuram et al. 2003), the performance of algorithms (both with regards to time requirements as well as solution quality) could be vastly improved by reducing the search space for possible schedules to only solutions with certain properties. Therefore, in order to further strengthen current scheduling algorithms for demand response problems, researches should focus on identifying and exploiting structural properties.

As described above, the problem of finding (near-)optimal production schedules while incorporating flexibility and energy prices is complex even when prices can be assumed to be deterministic for the planning horizon of the production. An additional major challenge stems from the increasing unpredictability and fluctuation of energy prices. For instance, if prices change during the day (for instance due to much lower supply of wind energy as compared to the forecast), the performance of the schedule might also change drastically. Stochastic and robust optimization are methods to cope with uncertainties in scheduling. While stochastic optimization has been applied to manage fluctuating energy supply (see Zakaria et al. (2020) for a recent survey), it has not been sufficiently studied how these methods can be applied on the individual consumer level in such a way that schedules can be adapted efficiently. Robust adaptable optimization (Bertsimas et al. 2011) can be a promising direction to address demand flexibility and changing electricity prices in production scheduling. It offers a two-stage framework to generate appropriate schedules based on the day-ahead prices but allows for enough flexibility to change the schedules during production based on the intraday market.

\section{Prosumers}

An increasingly active demand side changes the perception of electricity consumers. By means of small-scale generation installations (e.g., photovoltaic systems), storage devices (e.g., electric vehicles), and flexible electricity consumption, end consumers can actively participate in wholesale electricity markets. The term prosumer captures this hybrid role as both a consumer and a producer of electricity.

Prosumers typically do not participate in electricity markets directly. VPPs bundle the activities of prosumers and decentralized electricity generation facilities, actively buying and selling power on electricity markets (Kumagai 2012). In this section, we outline current research challenges related to VPPs. Besides, we will discuss the interrelation of prosumers and a future tariff design, as tariffs continue to be a central tool to incentivize demand response.

\subsection{How can cooperation and coordination of prosumers in virtual power plants be enabled?}

In essence, VPPs aggregate several decentralized assets and collectively trade electricity on their behalf. In this way, VPPs act as an intermediary for small assets that would otherwise not participate in electricity markets. Typically, the assets that form the VPP are centrally controlled by a system that interacts with electricity 
markets, receives price signals, and schedules the operations of the VPP assets accordingly (Naval and Yusta 2021).

This implies an inherent complex scheduling problem for VPPs. Several scheduling methods have been suggested, but open questions remain with respect to incorporating additional economic and technical aspects, e.g., technical network constraints, maintenance costs, or capital fees (Rouzbahani et al. 2021). Yu et al. (2019) summarize the major uncertainties for a VPP referring to renewable electricity production, market prices, and electricity demand. The authors discuss planning problems to enhance the performance of VPPs under such uncertainties, motivating further contributions by the business research community.

Moreover, the information and communication infrastructure and its implementation in a VPP (Pasetti et al. 2018) is an ongoing research topic. Here, distributed ledger technologies such as the blockchain, together with secure multi-party computation or self-sovereign identities, promise to enable and foster trustable (peerto-peer) energy trading in VPPs (Seven et al. 2020; Yang et al. 2021). The use of such technologies allows the members of a VPP to interact without explicitly sharing possibly confidential information on, e.g., their core production processes or the capacity of installed assets. In addition, smart contracts based on a blockchain technology can enable an automated settlement in VPPs and allow the automated execution of trading activities on a temporally very fine grained basis, which would otherwise not be possible with "manual decisions" (Lu et al. 2020). At the same time, an ex-ante agreed form of profit sharing - associated with the joint marketing of flexibility - can directly be enforced among the members of the VPP. Especially the business \& information systems engineering discipline can address questions related to the governance and technical design of the used blockchain (e.g., with respect to consensus mechanisms). Further questions relate to the data that should be stored on the blockchain itself and respective privacy concerns.

\subsection{How do end consumers respond to different electricity tariffs?}

One prerequisite for flexible prosumers is some form of exposure to wholesale electricity prices (e.g., through a VPP). Here, efforts should be devoted to examining how end consumers respond to different electricity tariffs and their respective incentives for demand response. Many concepts regarding the design of end consumer tariffs have been discussed. For instance, Grimm et al. (2021) consider the following four basic variants of tariff designs:

- Fixed-price tariff: prosumers pay a fixed baseline price per unit of energy consumption. This represents the most classical tariff design.

- Real-time pricing: the day-ahead wholesale electricity price is forwarded to the prosumer. The prosumer is thus directly exposed to electricity spot markets.

- Time-of-use tariffs: in this case, the contractual agreement between electricity provider and prosumer typically involves a partition into peak and off-peak periods. Next to a fixed baseline price, which is paid during off-peak periods, prosumers are charged an additional pre-determined markup for consumption during peak periods. 
- Critical-peak pricing: similar to time-of-use tariffs, a fixed baseline price is charged for off-peak periods, yet the markup for peak periods is not contractually agreed upon in advance.

While there is considerable evidence that the specific tariff structure sets important prosumer incentives and affects their behavior, the design of tariffs in the highly dynamic environment of electricity markets with increasing time and space granularity remains an active field of research (Ansarin et al. 2020; Nijhuis et al. 2017; Castro and Callaway 2020). Different tariffs come with different risk exposures for both retailers and prosumers. For instance, real-time pricing shifts all price risk to the prosumers, while time-of-use tariffs lead to a higher market exposure by the retailer (Grimm et al. 2021) - an issue currently heavily debated in the context of the global gas and electricity price crisis. Risk management and the design of optimal contract portfolios provide an interesting research direction for the finance community, and contribute to the functioning of novel tariff systems considering, e.g., volatile market prices or the (changing) demand behavior of consumers (Gilbert et al. 2015; Nojavan et al. 2017).

Mathematical programming is an established tool to evaluate different tariff designs. Advances in optimization can be used to capture new real-world complexities of modern electricity markets in the design and evaluation of tariffs (Castro and Callaway 2020). In particular, stochastic optimization techniques allow to integrate inherent sources of uncertainties, e.g., the price-elasticities of demand (de Sa Ferreira et al. 2013). The operations research discipline can leverage these advances to conceptualize and solve more sophisticated models, providing better justifications for different tariff designs.

As noted by Hall et al. (2016), prosumers need to be informed about the potential benefits of novel tariff designs (such as time-of-use or critical-peak pricing), using relevant knowledge about different customer groups, segments, and market-specific factors (e.g., the degree of risk aversion). However, currently there are still only limited insights regarding consumer preferences on dynamic pricing concepts (Dütschke and Paetz 2013). This calls for contributions by the marketing discipline towards a widespread establishment of appropriate tariff structures and new products/services on the basis of new information on customer preferences and behavior. For example, Li et al. (2016) already investigate the effects of different time-of-use tariffs on household demand response. There are numerous questions of this sort for marketing researchers, helping to better understand incentives set by different tariff structures.

\section{Conclusion}

The energy transition is arguably one of the greatest challenges of our time. Increasing capacities of VER shift central paradigms of electricity systems and require a rethinking of electricity markets. The energy transition is an inherently interdisciplinary project that requires a collaboration of natural sciences, engineering disciplines, economics as well as business research. In this paper, we aim to de- 
scribe major structural changes in electricity markets and their implications on key stakeholders.

First, increasing the spatial granularity of prices, e.g., by moving towards smaller pricing zones or even nodal pricing, allows to efficiently deal with growing levels of grid congestion and to set appropriate locational investment incentives for electricity generation and consumption units. Second, increasing the temporal granularity of market processes enables near real-time corrections of fast-changing VER supply and promotes an integration of flexible assets. Third, an active and flexible demand side is essential to compensate for the intermittency and uncertainty of low-carbon VER supply. These changes lead to a number of research problems for market operators, generators, industrial consumers, and retail customers. We demonstrate that business research can contribute in important ways and that it can be regarded as a critical enabler for a successful energy transition.

While we do not claim to provide an exhaustive list of research questions for business research in the context of the energy transition, we aim to showcase with this paper how business research - in close collaboration with other disciplines can contribute to managing this large economic and societal project. We hope that this call to arms motivates the significant role that business research can and should play in advancing the energy transition and, thus, in combating climate change.

Funding The authors gratefully acknowledge the financial support of the Kopernikus-Project "SynErgie" by the Federal Ministry of Education and Research of Germany (BMBF) and the project supervision by the project management organization Projektträger Jülich (PtJ).

Funding Open Access funding enabled and organized by Projekt DEAL.

Open Access This article is licensed under a Creative Commons Attribution 4.0 International License, which permits use, sharing, adaptation, distribution and reproduction in any medium or format, as long as you give appropriate credit to the original author(s) and the source, provide a link to the Creative Commons licence, and indicate if changes were made. The images or other third party material in this article are included in the article's Creative Commons licence, unless indicated otherwise in a credit line to the material. If material is not included in the article's Creative Commons licence and your intended use is not permitted by statutory regulation or exceeds the permitted use, you will need to obtain permission directly from the copyright holder. To view a copy of this licence, visit http://creativecommons.org/licenses/by/4. $0 \%$.

Conflict of interest There are no potential competing interests.

\section{References}

Adamec, M., M. Indrakova, and P. Pavlatka. 2009. Market coupling and price coordination between power exchanges. In Proceedings of the 10th IAEE European Conference: Energy, Policies and Technologies for Sustainable Economies. Vienna.

Agency for the Cooperation of Energy Regulators. 2015. Joint ACER-CEER response to European Commission's consultation on new energy market design

Aickelin, U., and K.A. Dowsland. 2000. Exploiting problem structure in a genetic algorithm approach to a nurse rostering problem. Journal of scheduling 3(3):139-153.

Alemany, J.M., B. Arendarski, P. Lombardi, and P. Komarnicki. 2018. Accentuating the renewable energy exploitation: evaluation of flexibility options. International Journal of Electrical Power \& Energy Systems 102:131-151.

Alomoush, M.I., and S.M. Shahidehpour. 2000. Generalized model for fixed transmission rights auction. Electric Power Systems Research 54(3):207-220. 
Ansarin, M., Y. Ghiassi-Farrokhfal, W. Ketter, and J. Collins. 2020. Cross-subsidies among residential electricity prosumers from tariff design and metering infrastructure. Energy Policy 145:111736.

Antonopoulos, G., S. Vitiello, G. Fulli, and M. Masera. 2020. Nodal pricing in the European internal electricity market. Vol. 30155 of EUR. Luxembourg: Publications Office of the European Union.

Araoz, V., and K. Jörnsten. 2011. Semi-Lagrangean approach for price discovery in markets with nonconvexities. European Journal of Operational Research 214(2):411-417.

Arrow, K.J., and G. Debreu. 1954. Existence of an equilibrium for a competitive economy. Econometrica: Journal of the Econometric Society 22(3):265-290. https://doi.org/10.2307/1907353.

Arunapuram, S., K. Mathur, and D. Solow. 2003. Vehicle routing and scheduling with full truckloads. Transportation Science 37(2):170-182.

Ashour Novirdoust, A., M. Bichler, C. Bojung, H.U. Buhl, G. Fridgen, V. Gretschko, L. Hanny, J. Knörr, F. Maldonado, K. Neuhoff, C. Neumann, M. Ott, J.C. Richstein, M. Rinck, M. Schöpf, P. Schott, A. Sitzmann, J. Wagner, J. Wagner, and M. Weibelzahl. 2021. Electricity spot market design 2030-2050

Bai, X., H. Wei, K. Fujisawa, and Y. Wang. 2008. Semidefinite programming for optimal power flow problems. International Journal of Electrical Power \& Energy Systems 30(6-7):383-392.

Baldwin, E., and P. Klemperer. 2019. Understanding preferences: demand types, and the existence of equilibrium with indivisibilities. Econometrica 87(3):867-932.

Bertsimas, D., D.B. Brown, and C. Caramanis. 2011. Theory and applications of robust optimization. SIAM review 53(3):464-501.

Bichler, M., and S. Waldherr. 2017. Core and pricing equilibria in combinatorial exchanges. Economics Letters 157:145-147.

Bichler, M., M. Fichtl, and G. Schwarz. 2020. Walrasian equilibria from an optimization perspective: A guide to the literature. Naval Research Logistics (NRL) 68(4):496-513. https://doi.org/10.1002/ nav. 21963.

Bikhchandani, S., and J.W. Mamer. 1997. Competitive equilibrium in an exchange economy with indivisibilities. Journal of economic theory 74(2):385-413.

BMWi. 2015. Making a success of the energy transition: On the road to a secure, clean and affordable energy supply

Bohn, R.E., M.C. Caramanis, and F.C. Schweppe. 1984. Optimal pricing in electrical networks over space and time. The Rand Journal of Economics 15(3):360-376. https://doi.org/10.2307/2555444.

Borenstein, S., and J. Bushnell. 2015. The US electricity industry after 20 years of restructuring. Annu. Rev. Econ 7(1):437-463.

Bruck, M., P. Sandborn, and N. Goudarzi. 2018. A levelized cost of energy (LCOE) model for wind farms that include power purchase agreements (PPAs). Renewable Energy 122:131-139.

Bublitz, A., D. Keles, F. Zimmermann, C. Fraunholz, and W. Fichtner. 2019. A survey on electricity market design: Insights from theory and real-world implementations of capacity remuneration mechanisms. Energy Economics 80:1059-1078.

Bundesnetzagentur, and Bundeskartellamt. 2021. Monitoringbericht 2020

Cain, M.B., R.P. O'neill, A. Castillo, et al, 2012. History of optimal power flow and formulations. Federal Energy Regulatory Commission 1:1-36.

California ISO. 2018. ISO At-A-Glance. https://www.caiso.com/Documents/CaliforniaISO-GeneralCompa nyBrochure.pdf. Accessed 15 Aug 2021.

California ISO. 2019a. Business practice manual for market operations. https://bpmcm.caiso.com/BPM \%20Document\%20Library/Market\%20Operations/BPM_for_Market\%20Operations_V61_redline. pdf. Accessed 15 Aug 2021.

California ISO. 2019b. Day-ahead market enhancements phase 1: Fifteen-minute granularity: third revised straw proposal

Caramizaru, A., and A. Uihlein. 2020. Energy communities: An overview of energy and social innovation. JRC science for policy report.. Luxembourg: Publications Office of the European Union.

Carpentier, J. 1985. Optimal power flows: uses, methods and developments. IFAC Proceedings Volumes 18(7):11-21.

Castillo, A., and R.P. O'Neill. 2013. Survey of approaches to solving the ACOPF (OPF paper 4). US Federal Energy Regulatory Commission, Tech. Rep.

Castro, F.A., and D.S. Callaway. 2020. Optimal electricity tariff design with demand-side investments. Energy Systems 11(3):551-579.

Chaiken, B., J.E. Duggan, and R. Sioshansi. 2021. Paid to produce absolutely nothing? A Nash-Cournot analysis of a proposed power purchase agreement. Energy Policy 156:112371.

Chao, H.-P., and S. Peck. 1996. A market mechanism for electric power transmission. Journal of regulatory economics 10(1):25-59. 
Clò, S., A. Cataldi, and P. Zoppoli. 2015. The merit-order effect in the Italian power market: the impact of solar and wind generation on national wholesale electricity prices. Energy Policy 77:79-88.

Coffrin, C., H.L. Hijazi, and P. Van Hentenryck. 2016. Strengthening the SDP relaxation of AC power flows with convex envelopes, bound tightening, and valid inequalities. IEEE Transactions on Power Systems 32(5):3549-3558.

Cramton, P. 2017. Electricity market design. Oxford Review of Economic Policy 33(4):589-612.

Cui, H., and K. Zhou. 2018. Industrial power load scheduling considering demand response. Journal of cleaner production 204:447-460.

Deng, S.-J., S. Oren, and A.P. Meliopoulos. 2010. The inherent inefficiency of simultaneously feasible financial transmission rights auctions. Energy Economics 32(4):779-785.

Dijk, J., and B. Willems. 2011. The effect of counter-trading on competition in electricity markets. Energy Policy 39(3):1764-1773.

Dütschke, E., and A.-G. Paetz. 2013. Dynamic electricity pricing-which programs do consumers prefer? Energy Policy 59:226-234.

Eldridge, B., Richard P.O. 'Neill, and A. Castillo. 2017. Marginal loss calculations for the DCOPF

ENTSO-E. 2021. Options for the design of European electricity markets in 2030: Discussion paper for stakeholder consultation

EU. 2016. Impact assessment study on downstream flexibility, price flexibility, demand response \& smart metering. Technical Report ENER/B3/2015-641.

Farivar, M., C.R. Clarke, S.H. Low, and K.M. Chandy. 2011. Inverter VAR control for distribution systems with renewables. In 2011 IEEE International Conference on Smart Grid Communications (SmartGridComm), 457-462. : IEEE.

Federal Energy Regulatory Commission. 2020. Energy price formation

Frank, S., I. Steponavice, and S. Rebennack. 2012. Optimal power flow: a bibliographic survey I and II. Energy systems 3(3):221-289.

Fridgen, G., A. Michaelis, M. Rinck, M. Schöpf, and M. Weibelzahl. 2020. The search for the perfect match: aligning power-trading products to the energy transition. Energy Policy 144:111523.

Garcia, M., H. Nagarajan, and R. Baldick. 2020. Generalized convex hull pricing for the AC optimal power flow problem. IEEE Transactions on Control of Network Systems 7(3):1500-1510.

Gelabert, L., X. Labandeira, and P. Linares. 2011. An ex-post analysis of the effect of renewables and cogeneration on spanish electricity prices. Energy Economics 33:S59-S65.

Ghiassi-Farrokhfal, Y., W. Ketter, and J. Collins. 2021. Making green power purchase agreements more predictable and reliable for companies. Decision Support Systems 144:113514.

Gilbert, F., M.F. Anjos, P. Marcotte, and G. Savard. 2015. Optimal design of bilateral contracts for energy procurement. European Journal of Operational Research 246(2):641-650.

Glenk, G., R. Meier, and S. Reichelstein. 2021. Cost dynamics of clean energy technologies. Schmalenbach Journal of Business Research 73:179-206. https://doi.org/10.1007/s41471-021-00114-8.

Grimm, V., A. Martin, M. Schmidt, M. Weibelzahl, and G. Zöttl. 2016. Transmission and generation investment in electricity markets: the effects of market splitting and network fee regimes. European Journal of Operational Research 254(2):493-509.

Grimm, V., B. Rückel, C. Sölch, and G. Zöttl. 2020. The impact of market design on transmission and generation investment in electricity markets. Energy Economics 93:104934. https://doi.org/10.1016/ j.eneco.2020.104934.

Grimm, V., G. Orlinskaya, L. Schewe, M. Schmidt, and G. Zöttl. 2021. Optimal design of retailer-prosumer electricity tariffs using bilevel optimization. Omega 102:102327.

Hall, N.L., T.D. Jeanneret, and A. Rai. 2016. Cost-reflective electricity pricing: consumer preferences and perceptions. Energy Policy 95:62-72.

Haupt, L., M.-F. Körner, M. Schöpf, P. Schott, and G. Fridgen. 2020. Strukturierte Analyse von Nachfrageflexibilität im Stromsystem und Ableitung eines generischen Geschäftsmodells für (stromintensive) Unternehmen. Zeitschrift für Energiewirtschaft 44(2):141-160.

Herrero, I., P. Rodilla, and C. Batlle. 2020. Evolving bidding formats and pricing schemes in USA and Europe day-ahead electricity markets. Energies 13(19):5020.

Hijazi, H., C. Coffrin, and P. van Hentenryck. 2017. Convex quadratic relaxations for mixed-integer nonlinear programs in power systems. Mathematical Programming Computation 9(3):321-367.

Hogan, W.W. 1992. Contract networks for electric power transmission. Journal of Regulatory Economics 4(3):211-242.

Hogan, W.W. 2002. Electricity market restructuring: reforms of reforms. Journal of Regulatory Economics 21(1):103-132. 
Hogan, W.W. 2013. Financial transmission rights, revenue adequacy and multi-settlement electricity markets

Hogan, W.W., et al. 2005. On an "energy only" electricity market design for resource adequacy

Hytowitz, R.B., B. Frew, G. Stephen, E. Ela, N. Singhal, A. Bloom, and J. Lau. 2020. Impacts of price formation efforts considering high renewable penetration levels and system resource adequacy targets

IPCC. 2018. Global warming of $1.5^{\circ} \mathrm{c}$ : Special report

IRENA. 2017. Adapting market design to high shares of variable renewable energy

IRENA. 2019a. Demand-side flexibility for power sector transformation- analytical brief. Technical report, IRENA. https://www.irena.org/-/media/Files/IRENA/Agency/Publication/2019/Dec/IRENA_ Demand-side_flexibility_2019.pdf. Accessed 30 Aug 2021.

IRENA. 2019b. Innovation landscape for a renewable-powered future: solutions to integrate variable renewables

Jabr, R.A. 2006. Radial distribution load flow using conic programming. IEEE Transactions on Power Systems 21(3):1458-1459.

Jäckle, F., M. Schöpf, J. Töppel, and F. Wagon. 2019. Risk mitigation capability of flexibility performance contracts for demand response in electricity systems. In 27th European Conference on Information Systems (ECIS).

Kemfert, C. 2005. The economic costs of climate change

Kender, R., F. Kaufmann, F. Rößler, B. Wunderlich, D. Golubev, I. Thomas, A.-M. Ecker, S. Rehfeldt, and H. Klein. 2021. Development of a digital twin for a flexible air separation unit using a pressure-driven simulation approach. Computers \& Chemical Engineering 151:107349.

Keramidas, K., A. Diaz Vazquez, M. Weitzel, T. Vandyck, M. Tamba, S. Tchung-Ming, A. Soria-Ramirez, J. Krause, R. van Dingenen, Q. Chai, S. Fu, and X. Wen. 2020. Electrification for the low-carbon transition: the role of electrification in low-carbon pathways, with a global and regional focus on EU and China

Kim, S. 1986. Computation of a large-scale competitive equilibrium through optimization. Computers and Operations Research 13(4):507-515.

Kumagai, J. 2012. Virtual power plants, real power. IEEE Spectrum 49(3):13-14.

Kwoka, J. 2008. Restructuring the US electric power sector: a review of recent studies. Review of Industrial Organization 32(3-4):165-196.

Lei, N., L. Chen, C. Sun, and Y. Tao. 2018. Electricity market creation in China: policy options from political economics perspective. Sustainability 10(5):1481.

Leme, R.P. 2017. Gross substitutability: an algorithmic survey. Games and Economic Behavior 106:294-316.

Li, W., P. Xu, X. Lu, H. Wang, and Z. Pang. 2016. Electricity demand response in China: status, feasible market schemes and pilots. Energy 114:981-994.

Liberopoulos, G., and P. Andrianesis. 2016. Critical review of pricing schemes in markets with non-convex costs. Operations Research 64(1):17-31.

London Economic International LLC. 2020. Review of PJM's auction revenue rights and financial transmission rights

Low, S.H. 2014a. Convex relaxation of optimal power flow-part I: Formulations and equivalence. IEEE Transactions on Control of Network Systems 1(1):15-27.

Low, S.H. 2014b. Convex relaxation of optimal power flow-part II: Exactness. IEEE Transactions on Control of Network Systems 1(2):177-189.

Lu, J., S. Wu, H. Cheng, and Z. Xiang. 2020. Smart contract for distributed energy trading in virtual power plants based on blockchain. Computational Intelligence 37(3):1445-1455. https://doi.org/10. 1111/coin. 12388 .

Lund, P.D., J. Lindgren, J. Mikkola, and J. Salpakari. 2015. Review of energy system flexibility measures to enable high levels of variable renewable electricity. Renewable and sustainable energy reviews 45:785-807.

Meeus, L., L. Vandezande, S. Cole, and R. Belmans. 2009a. Market coupling and the importance of price coordination between power exchanges. Energy 34(3):228-234.

Meeus, L., K. Verhaegen, and R. Belmans. 2009b. Block order restrictions in combinatorial electric energy auctions. European Journal of Operational Research 196(3):1202-1206.

Mendicino, L., D. Menniti, A. Pinnarelli, and N. Sorrentino. 2019. Corporate power purchase agreement: Formulation of the related levelized cost of energy and its application to a real life case study. Applied Energy 253:113577.

Molzahn, D.K., and I.A. Hiskens. 2014. Moment-based relaxation of the optimal power flow problem. In 2014 Power Systems Computation Conference, 1-7. : IEEE. 
Molzahn, D.K., and I.A. Hiskens, et al. 2019. A survey of relaxations and approximations of the power flow equations

Munoz, F.D., S. Wogrin, S.S. Oren, and B.F. Hobbs. 2018. Economic inefficiencies of cost-based electricity market designs. The Energy Journal 39(3):51-68. https://doi.org/10.5547/01956574.39.3.fmun.

Naval, N., and J.M. Yusta. 2021. Virtual power plant models and electricity markets - a review. Renewable and Sustainable Energy Reviews 149:111393.

NEMO Committee. 2019. CACM апnиal report 2018

NEMO Committee. 2021. САCM апnиal report 2020

Nijhuis, M., M. Gibescu, and J. Cobben. 2017. Analysis of reflectivity \& predictability of electricity network tariff structures for household consumers. Energy Policy 109:631-641.

Nojavan, S., K. Zare, and B. Mohammadi-Ivatloo. 2017. Optimal stochastic energy management of retailer based on selling price determination under smart grid environment in the presence of demand response program. Applied Energy 187:449-464.

O'Neill, R.P., P.M. Sotkiewicz, B.F. Hobbs, M.H. Rothkopf, and W.R. Stewart. 2005. Efficient market-clearing prices in markets with nonconvexities. European Journal of Operational Research 1(164):269-285.

O'Neill, R.P., T. Dautel, and E. Krall. 2011. Recent ISO software enhancements and future software and modeling plans

O'Neill, R., R.B. Hytowitz, P. Whitman, D. Mead, T. Dautel, Y. Chen, B. Eldridge, A. Siskind, D. Kheloussi, D. Kolkmann, A. Smith, A. Castillo, and J. Mays. 2019. Essays on average incremental cost pricing for independent system operators

Palensky, P., and D. Dietrich. 2011. Demand side management: demand response, intelligent energy systems, and smart loads. IEEE transactions on industrial informatics 7(3):381-388.

Behnke, Palma, Rodrigo Ernesto G. Jiménez Estévez, and I. Alarcón Arias. 2009. Las energías renovables no convencionales en el mercado eléctrico chileno. : Comisión Nacional de Energía.

Papaefthymiou, G., E. Haesen, and T. Sach. 2018. Power system flexibility tracker: Indicators to track flexibility progress towards high-RES systems. Renewable energy 127:1026-1035.

Papavasiliou, A. 2020. Scarcity pricing and the missing European market for real-time reserve capacity. The Electricity Journal 33(10):106863.

Pasetti, M., S. Rinaldi, and D. Manerba. 2018. A virtual power plant architecture for the demand-side management of smart prosumers. Applied Sciences 8(3):432.

Paukstadt, U., and J. Becker. 2021. From energy as a commodity to energy as a service-a morphological analysis of smart energy services. Schmalenbach Journal of Business Research 73:207-242. https:// doi.org/10.1007/s41471-021-00111-x.

Qiu, Z., G. Deconinck, and R. Belmans. 2009. A literature survey of optimal power flow problems in the electricity market context. In 2009 IEEE/PES Power Systems Conference and Exposition, 1-6. : IEEE.

Raftery, A.E., A. Zimmer, D.M. Frierson, R. Startz, and P. Liu. 2017. Less than $2^{\circ} \mathrm{C}$ warming by 2100 unlikely. Nature climate change 7(9):637-641.

Raikar, S., and S. Adamson. 2020. Alternative off-take strategies and managing merchant risks. In Renewable Energy Finance, 141-159. : Elsevier.

Reihani, E., M. Motalleb, M. Thornton, and R. Ghorbani. 2016. A novel approach using flexible scheduling and aggregation to optimize demand response in the developing interactive grid market architecture. Applied energy 183:445-455.

Richstein, J.C., C. Lorenz, and K. Neuhoff. 2020. An auction story: How simple bids struggle with uncertainty. Energy Economics 89:104784. https://doi.org/10.1016/j.eneco.2020.104784.

Rouzbahani, H.M., H. Karimipour, and L. Lei. 2021. A review on virtual power plant for energy management. Sustainable Energy Technologies and Assessments 47:101370.

de Sa Ferreira, R., L.A. Barroso, P. Lino Rochinha, M.M. Carvalho, and P. Valenzuela. 2013. Time-of-use tariff design under uncertainty in price-elasticities of electricity demand: A stochastic optimization approach. IEEE Transactions on Smart Grid 4(4):2285-2295.

Schilling, R. 2019. Purchasing power becomes a treasury topic: risk management for power purchase agreements

Schiro, D.A., T. Zheng, F. Zhao, and E. Litvinov. 2016. Convex hull pricing in electricity markets: formulation, analysis, and implementation challenges. IEEE Transactions on Power Systems 31(5):4068-4075.

Schmidt, L., and J. Zinke. 2020. One price fits all? Wind power expansion under uniform and nodal pricing in Germany: EWI working paper 
Schoepf, M., M. Weibelzahl, and L. Nowka. 2018. The impact of substituting production technologies on the economic demand response potential in industrial processes. Energies 11(9):2217.

Schott, P., J. Sedlmeir, N. Strobel, T. Weber, G. Fridgen, and E. Abele. 2019. A generic data model for describing flexibility in power markets. Energies 12(10):1893.

Sensfuß, F., M. Ragwitz, and M. Genoese. 2008. The merit-order effect: A detailed analysis of the price effect of renewable electricity generation on spot market prices in Germany. Energy Policy 36(8):3086-3094.

Seven, S., G. Yao, A. Soran, A. Onen, and S. Muyeen. 2020. Peer-to-peer energy trading in virtual power plant based on blockchain smart contracts. IEEE Access 8:175713-175726.

Shah, D., and S. Chatterjee. 2020. A comprehensive review on day-ahead electricity market and important features of world's major electric power exchanges. International Transactions on Electrical Energy Systems 30(7):e12360. https://doi.org/10.1002/2050-7038.12360.

Sioshansi, F. 2021. Variable generation, flexible demand. : Elsevier.

Stoft, S. 2002. Power system economics: Designing markets for electricity. Piscataway, New Jersey, New York: IEEE Press Wiley-Interscience and IEEE Xplore.

Sun, A.X., D.T. Phan, and S. Ghosh. 2013. Fully decentralized AC optimal power flow algorithms. In 2013 IEEE Power \& Energy Society General Meeting, 1-5. : IEEE.

Toczyłowski, E., and I. Zoltowska. 2009. A new pricing scheme for a multi-period pool-based electricity auction. European Journal of Operational Research 197(3):1051-1062.

trend:research GmbH. 2013. Definition und Marktanalyse von Bürgerenergie in Deutschland

Weibelzahl, M. 2017. Nodal, zonal, or uniform electricity pricing: how to deal with network congestion. Frontiers in Energy 11(2):210-232.

Wichmann, M.G., C. Johannes, and T.S. Spengler. 2019a. Energy-oriented lot-sizing and scheduling considering energy storages. International Journal of Production Economics 216:204-214.

Wichmann, M.G., C. Johannes, and T.S. Spengler. 2019b. An extension of the general lot-sizing and scheduling problem (GLSP) with time-dependent energy prices. Journal of Business Economics 89(5):481-514.

Wolak, F.A. 2021. Market design in an intermittent renewable future: Cost recovery with zero-marginalcost resources. IEEE Power and Energy Magazine 19(1):29-40.

Woo, C.K., I. Horowitz, J. Moore, and A. Pacheco. 2011. The impact of wind generation on the electricity spot-market price level and variance: the texas experience. Energy Policy 39(7):3939-3944.

World Meteorological Organization. 2020. State of the global climate 2020

$\mathrm{Wu}$, O.Q., and V. Babich. 2012. Unit-contingent power purchase agreement and asymmetric information about plant outage. Manufacturing \& Service Operations Management 14(2):245-261.

Yang, Q., H. Wang, T. Wang, S. Zhang, X. Wu, and H. Wang. 2021. Blockchain-based decentralized energy management platform for residential distributed energy resources in a virtual power plant. Applied Energy 294:117026.

Yu, S., F. Fang, Y. Liu, and J. Liu. 2019. Uncertainties of virtual power plant: Problems and countermeasures. Applied Energy 239:454-470.

Zakaria, A., F.B. Ismail, M.H. Lipu, and M.A. Hannan. 2020. Uncertainty models for stochastic optimization in renewable energy applications. Renewable Energy 145:1543-1571.

Zohrizadeh, F., C. Josz, M. Jin, R. Madani, J. Lavaei, and S. Sojoudi. 2020. A survey on conic relaxations of optimal power flow problem. European Journal of Operational Research 287(2):391-409. 